\title{
CORRESPONDENCE
}

\section{Pharmacist interventions in asthma}

\section{To the Editors:}

The paper by MenuYs et al. [1] adds to the body of literature which demonstrates the utility of pharmacist-led disease management interventions in improving asthma care. The intervention in this study included education about asthma management, inhaler technique, medication adherence and, in some cases, smoking cessation. The multi-facilitated approach of this and several previous studies raises the question of which particular element(s) contributed to the improved asthma outcomes. BASHETI and co-workers [2, 3] have shown that a pharmacist intervention targeting only dry powder inhaler technique was effective in improving asthma control and asthma-related quality of life compared with a "sham" intervention (teaching peak flow meter technique). In this study, the intervention was delivered in an average of only $2.5 \mathrm{~min}$ per visit, suggesting that it should be feasible for incorporation into normal pharmacy practice.

In light of this, it would be helpful for E. Mehuys and coworkers to provide information about which intervention components were delivered at each study visit, and the total time taken per visit for intervention and usual care groups.

Finally, although inhaler technique in this study was not checked when asthma was well controlled, we believe that inhaler technique should be checked in all patients at all visits. Inhaler technique deteriorates within 2-3 months of an educational intervention $[2,4]$. Poor inhaler technique may contribute not only to poor asthma control but also, in patients with good asthma control, to a continuing need for high prescribed doses of inhaled corticosteroids. In clinical practice, improvement in incorrect inhaler technique may allow reduction in prescribed doses, with potential reduction in local side effects and cost to the community.

\section{H.K. Reddel*, S.Z. Bosnic-Anticevich ${ }^{\#}$, C.L. Amour ${ }^{\#}$ and I. Basheti"}

*Woolcock Institute of Medical Research, Camperdown, and "University of Sydney, Sydney, Australia. "Applied Science University, Amman, Jordan.

\section{STATEMENT OF INTEREST}

None declared.

\section{REFERENCES}

1 Mehuys E, Van Bortel L, De Bolle L, et al. Effectiveness of pharmacist intervention for asthma control improvement. Eur Respir J 2008; 31: 790-799.

2 Basheti IA, Reddel HK, Armour CL, Bosnic-Anticevich SZ. Improved asthma outcomes with a simple inhaler technique intervention by community pharmacists. J Allergy Clin Immunol 2007; 119: 1537-1538.

3 Basheti IA, Armour CL, Bosnic-Anticevich SZ, Reddel HK. Evaluation of a novel educational strategy, including inhaler-based reminder labels, to improve asthma inhaler technique. Patient Educ Couns 2008; 72: 26-33.

4 O'Connell MB, Hewitt JM, Lackner TE, Pastor JD 3rd, Wong MT, Bishop AL, Short- and long-term retention of a nursing home education program on metered-dose inhaler technique. Ann Pharmacother 1992; 26: 980-984.

DOI: $10.1183 / 09031936.00069508$

\section{From the authors:}

H.K. Reddel and co-workers refer to a paper by BASHETI et al. [1], describing a pharmacist intervention targeting only dry powder inhaler technique and taking $\sim 2.5 \mathrm{~min}$ per visit. First, we agree that ideally this intervention should be delivered to all asthma patients. Our intervention comprised more than just inhaler technique, as we also delivered education about asthma management, medication adherence and smoking cessation at visit 1 , and advice on the function of the patient's current Asthma Control Test $\mathbb{R}$ (ACT) score at visits 2 and 3 (see table 1 of reference [2]). Since this multi-faceted approach is more time consuming ( $\sim 20-30 \mathrm{~min}$ at visit 1 and $5-10 \mathrm{~min}$ at later visits), it should be delivered especially to those asthma patients who need it the most, i.e. the patients who are not well controlled (having an ACT score $<20$ ).

Secondly, we agree that inhaler technique should not only be checked in uncontrolled patients but also in controlled patients. A regular check of inhaler technique in well-controlled patients may indeed allow dose reduction of inhaled corticosteroids.

\section{E. Mehuys* and G. Brusselle ${ }^{\#}$}

*Pharmaceutical Care Unit, and "Dept of Respiratory Diseases, Ghent University Hospital, Ghent, Belgium.

\section{STATEMENT OF INTEREST}

None declared.

\section{REFERENCES}

1 Basheti IA, Reddel HK, Armour CL, Bosnic-Anticevich SZ. Improved asthma outcomes with a simple inhaler technique intervention by community pharmacists. J Allergy Clin Immunol 2007; 119: 1537-1538.

2 Mehuys E, Van Bortel L, De Bolle L, et al. Effectiveness of pharmacist intervention for asthma control improvement. Eur Respir J 2008; 31: 790-799.

DOI: $10.1183 / 09031936.00071108$ 